As-Syifaa Jurnal Farmasi Juli 2020;12(1):1-8.

ISSN : 2502-9444 (electronic); 2085-4714 (printed)

Journal Homepage : http://jurnal.farmasi.umi.ac.id/index.php/as-syifaa

\title{
PEMANFATAN LIMBAH RAMBUT JAGUNG BAKAR (Zea Mays L. sacharata) SEBAGAI KRIM ANTIOKSIDAN DAN TABIR SURYA
}

\author{
Sony Andika Saputra ${ }^{1}$, Munifatul Lailiyah² \\ ${ }^{1}$ Fakultas Sains, Teknologi dan Analisis Institut IImu Kesehatan Bhakti Wiyata Kediri \\ ${ }^{2}$ Fakultas Farmasi, Institut IImu Kesehatan Bhakti Wiyata Kediri \\ Email: sony.saputra@iik.ac.id
}

\begin{abstract}
Continuous sun exposure to the skin will cause skin damage due to the oxidative effects of free radicals. Phenolic compounds in the form of antioxidants can act as sunscreens to prevent adverse effects due to UV radiation. Positive corn silk contains phenols and flavonoids, which are compounds that have the potential to act as sunscreens and anti-oxidants. This research method was carried out by collecting roasted corn hair waste samples to be made dry simplicia, then extraction extraction with $70 \%$ ethanol solvent. The extract obtained was then formulated into a cream with a concentration variation of 1, 5 and $10 \%$. Furthermore, an evaluation of the physical quality of the cream preparation and antioxidant activity test using the DPPH method were also tested for the SPF value. The results showed that the evaluation of the quality of the cream preparations met the requirements. The antioxidant activity test of cream preparations is categorized as very weak. Test the SPF value of cream preparations including the maximum protection category in formulation III.
\end{abstract}

Key Words: DPPH, SPF, Cream

\section{PENDAHULUAN}

Sinar matahari yang terus menerus memapari kulit akan menyebabkan kerusakan kulit karena efek oksidatif radikal bebas. ${ }^{2}$ Adanya sinar ultraviolet (UV) dari sinar matahari dapat menyebabkan eritema, pigmentasi, fotosensitifitas, penuaan dini dan kanker kulit. $^{3}$ Senyawa fenolik yang berupa antioksidan dapat berperan sebagai tabir surya untuk mencegah efek yang merugikan akibat radiasi UV pada kulit karena anti oksidan sebagai fotoprotektif. ${ }^{4}$

Hasil dari penapisan fitokimia menunjukkan rambut jagung positif mengandung fenol dan flavonid, yang merupakan suatu senyawa yang berpotensi sebagai tabir surya dan anti oksidan. ${ }^{5}$ Aktivitas antioksidan ekstrak etanol rambut jagung mempunyai nilai IC 50 sebesar 143,55 ppm. ${ }^{6}$ Nilai SPF hasil fraksinasi ekstrak etanol rambut jagung didapatkan $9-25 .^{3}$
Krim merupakan sediaan kosmetik yang digunakan sebagai perlindungan kulit bagian luar yang mempunyai keuntungan, mudah diaplikasikan, lebih nyaman digunakan, tidak lengket dan mudah dicuci dengan air. ${ }^{2}$

Limbah rambut jagung selama ini belum dimanfaatkan secara maksimal, khususnya limbah dari rambut jagung bakar (Zea Mays L. sacharata) di Bundaran Taman Sekar Taji Kediri. Ekstrak rambut jagung bakar yang didapat diformulasikan ke dalam sediaan krim anti oksidan dan tabir surya. Penentuan aktivitas antioksidan dilakukan dengan menggunakan metode Diphenylhydrazy/picryl (DPPH) dan penentuan nilai SPF (Sun Protection Factor) dengan metode spektrofotometri.

\section{METODE PENELITIAN}

\section{Alat dan Bahan}

Peralatan yang dipakai dalam penelitian ini adalah neraca analitik (Mettler, Japan), pipet 
Pemanfatan Limbah Rambut Jagung Bakar (Zea Mays L. sacharata) Sebagai Krim Antioksidan Dan Tabir Surya

mikro, mesin pembuat serbuk, dikeringkan dengan cara diangin anginkan dan spektrofotometer UV-Vis, lemari pendingin, rotary evaporator (Buchi), alat-alat gelas. Bahan yang digunakan penelitian ini adalah Limbah Rambut Jagung Bakar (Zea Mays L. sacharata), DPPH (1,1 difenil-2-pikrilhidrazil), etanol, metanol, aquadest. Bahan pembuatan krim: Asam stearat, Setil alkohol, Trietanolamin, Parafin Cair, Minyak Zaitun, Gliserin, Metil paraben, Propil Paraben.

\section{Prosedur Penelitian}

\section{Persiapan Simplisia}

Sampel berupa rambut jagung manis segar berasal dari limbah jagung bakar di sekitaran bundaran taman Sekar Taji Kediri. Sampel disortir kemudian, dicuci, dirajang, terhindar dari sinar matahari langsung, lalu digiling. $^{3}$

\section{Ekstraksi Rambut Jagung (Zea Mays L. Sacharata)}

Pembuatan ekstrak rambut jagung dilakukan dengan metode maserasi, yaitu ditimbang simplisia rambut jagung sebanyak $400 \mathrm{~g}$ lalu diekstraksi dengan $3000 \mathrm{~mL}$ etanol $70 \%$ dengan cara maserasi selama 5 hari terlindung dari cahaya, setelah lima hari diserkai. Filtrat ditampung dan residu ditambah etanol $70 \%$ sebanyak $1000 \mathrm{ml}$, kemudian diserkai kembali. Filtrat dari hasil maserasi kemudian diuapkan di rotari evaporator pada suhu $60^{\circ} \mathrm{C}$ kemudian diperoleh ekstrak cair. ${ }^{7}$

\section{Formula Krim}

Tabel 1. Rancangan Formulasi Krim Ekstrak Rambut Jagung (Zea Mays L. Sacharata)

\begin{tabular}{lcccc}
\hline \multirow{2}{*}{ Formula } & \multicolumn{4}{c}{ \% Kadar } \\
\cline { 2 - 5 } & Kontrol & F1 & F2 & F3 \\
\hline Ekstrak terpurifikasi rambut jagung & - & 1 & 5 & 10 \\
Asam Stearat & 5 & 5 & 5 & 5 \\
Setil Alkohol & 3 & 3 & 3 & 3 \\
TEA & 1 & 1 & 1 & 1 \\
Parafin Cair & 7 & 7 & 7 & 7 \\
Minyak Zaitun & 10 & 10 & 10 & 10 \\
Gliserin & 7 & 7 & 7 & 7 \\
Nipagin & 0,025 & 0,025 & 0,025 & 0,025 \\
Nipasol & 0,015 & 0,015 & 0,015 & 0,015 \\
Aquades & 100 & 100 & 100 & 100 \\
\hline
\end{tabular}

\section{Pembuatan Krim Ekstrak Rambut Jagung}

\section{(Zea Mays L. Sacharata)}

Ditimbang semua bahan yang diperlukan bahan yang terdapat dalam formula dipisahkan menjadi dua kelompok yaitu fase minyakyang terdiri dari asan stearat, seti alkohol, parafin cair, minyak zaitun dan nipagin, dilebur diatas penangas air dengan suhu $70^{\circ} \mathrm{C}-75^{\circ} \mathrm{C}$. disamping itu fase air yang terdiri dari TEA, gliserin, nipasol dilarutan dalam aquadest panas. Digerus fase air dalam mortir panas, kemudian ditambahkan fase minyak sedikit demi sedikit aduk sampai homogen hingga diperoleh masa krim. Ditambahkan ekstrak terpurifikasi rambut jagung sedikit demi sedikit digerus hingga homogen. ${ }^{8}$

\section{Pengujian Sifat Fisis krim Ekstrak Rambut Jagung (Zea Mays L. Sacharata)}

Uji sifat fisis krim dilakukan dengan menguji, organoleptis, homogenitas, pengukuran $\mathrm{pH}$, viskositas, daya sebar, daya lekat, tipe krim. ${ }^{2}$ 
Pemanfatan Limbah Rambut Jagung Bakar (Zea Mays L. sacharata) Sebagai Krim Antioksidan Dan Tabir Surya

Uji Aktivitas antioksidan ekstrak etanol rambut jagung (Zea Mays L. Sacharata) dengan metode DPPH

\section{Pembuatan pereaksi DPPH}

DPPH ditimbang sebanyak $10 \mathrm{mg}$ kemudian dilarutkan ke dalam labu ukur $50 \mathrm{~mL}$ di tambah metanol ad tanda batas. Dari labu ukur kemudian dipipet $12,5 \mathrm{~mL}$ kemudian dimasukkan ke labu $50 \mathrm{~mL}$ dan di tambah methanol ad tanda batas sehingga didapat konsentrasi larutan DPPH 50 ppm.

Penentuan Panjang Gelombang Maksimum

Sebanyak 1,25 mL larutan DPPH 50 ppm kemudian ditambah metanol $3,75 \mathrm{~mL}$, dihomogenkan kemudian dibiarkan selama 30 menit diruang gelap. Serapan larutan diukur pada alat spektrofotometer UV-Vis pada panjang gelombang 500-524 nm.

Pemeriksaan uji aktivitas krim antioksidan Ekstrak Etanol Rambut Jagung (Zea Mays L. Sacharata)

\section{HASIL DAN PEMBAHASAN}

Tabel 2. Hasil Organoleptis Sediaan Krim Antioksidan dan Tabir surya Ekstrak Rambut Jagung (Zea Mays L. Sacharata)

\begin{tabular}{ccccc}
\hline Formula & \multicolumn{1}{c}{ Bentuk } & Tekstur & Warna & Bau \\
\hline Basis & krim/semisolida/setengah padat & Lembut & putih & Khas basis \\
F1 & krim/semisolida/setengah padat & Lembut & putih & khas \\
F2 & krim/semisolida/setengah padat & Lembut & putih pucat & khas \\
F3 & krim/semisolida/setengah padat & Lembut & putih agak kecoklatan & khas \\
\hline Keterangan : (F1) Konsentrasi ekstra rambut jagung 1\%; (F2) Konsentrasi ekstra rambut jagung 5\%; (F3) Konsentrasi ekstra \\
rambut jagung 10\%.
\end{tabular}

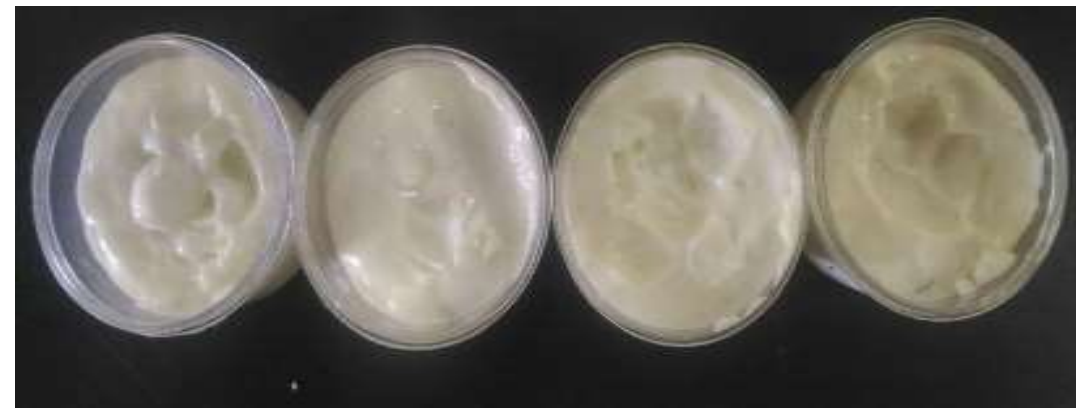

Gambar 1. Pengamatan organoleptis krim antioksidan dan tabir surya ekstrak rambut jagung (Zea Mays L. Sacharata)

\begin{abstract}
Pengukuran dilakukan dengan menggunakan berbagai konsentrasi krim ekstrak rambut jagung 50, 100, 200, 400 dan 600 ppm. Masing-masing konsentrasi krim ekstrak dipipet sejumlah $0,5 \mathrm{~mL}$ dan ditambah larutan DPPH $50 \mathrm{ppm}$ sebanyak $3,5 \mathrm{~mL}$, lalu dihomogenkan dibiarkan selama 30 menit terlindung dari cahaya kemudian diukur pada panjang gelombang maksimum pada $\lambda 516$ nm. ${ }^{9}$
\end{abstract}

\section{Penentuan Nilai SPF}

Penentuan nilai SPF menggunakan metode spektrofotometri, tiap formula ditimbang $1 \mathrm{~g}$ dilarutkan ke dalam labu ukur 25 $\mathrm{mL}$ kemudian di tambah etanol sampai tanda batas kemudian disaring. Kemudian larutan diukur absorbansinya pada $\lambda$ 290-320 nm dengan interfal pengukuran sebesar $5 \mathrm{~nm}$ menggunakan metode spektrofotometri UVVis. $^{3}$ 


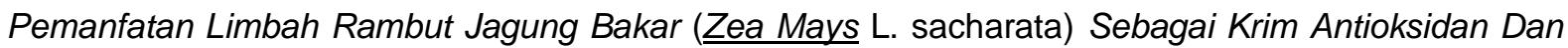
Tabir Surya

Uji organopleptis dimaksudkan untuk melihat tampilan krim secara fisik, yaitu meliputi bentuk, tekstur, warna, bau dari sediaan itu sendiri. Hasil evaluasi mutu fisik uji organoleptis didapatkan bentuk krim setengah padat, dengan warna putih untuk basis dan formulasi 1 , untuk formulasi 2 memiliki warna yang putih pucat dan formulasi 3 memiliki warna putih agak kecoklatan. Hal ini karena banyaknya ekstrak yang digunaan menggunakan konsentrasi yang berbeda yaitu F1 1\%, F2 5\% dan F3 10\% sehingga warna yang dihasilkan berbeda, semakin banyak ekstrak yang digunakan warna krim akan semakin gelap atau agak kecoklatan, tekstur yang lembut dan bau yang tidak berbau untuk basisnya sedangkan untuk Formulasi 1, Formulasi 2 dan Formulasi 3 memiliki bau khas ekstrak rambut jagung. Hasil uji organoleptis dapat dilihat tabel 2.

Tabel 3. Hasil Pengujian Homogenitas Krim Ekstrak Rambut Jagung (Zea Mays L. Sacharata)

\begin{tabular}{|c|c|}
\hline Formula & Homogenitas \\
\hline F 1 & Homogen \\
\hline F 2 & Homogen \\
\hline F 3 & Homogen \\
\hline \multicolumn{2}{|c|}{$\begin{array}{l}\text { Keterangan : (F1) Konsentrasi ekstra rambut jagung 1\%; (F2) Konsentrasi ekstra rambut jagung 5\%; (F3) Konsentrasi ekstra } \\
\text { rambut jagung 10\%. }\end{array}$} \\
\hline Hasil uji mutu fisik berikutnya adalah uji & yang homogen yang ditandai dengan tidak \\
\hline homogenistas yang merupakan pengujian & terdapatnya bintik-bintik atau butiran kasar, hal \\
\hline terhadap ketercampuran bahan-bahan dalam & ini sesuai dengan persyaratan homogenitas \\
\hline sediaan krim yang menunjukkan susunan yang & krim yaitu harus menunjukkan susunan yang \\
\hline homogen. Hasil dari pengujian didapatkan & tidak ada butiran kasar atau bintik-bintik. ${ }^{10}$ Hasil \\
\hline bahwa F1, F2 dan F3 menunjukkan susunan & uji homogenitas dapat dilihat pada tabel 3 . \\
\hline
\end{tabular}

Tabel 4. Hasil Pengujian Tipe Krim Ekstrak Rambut Jagung (Zea Mays L. Sacharata)

\begin{tabular}{cc}
\hline Formula & Homogenitas \\
\hline F 1 & O/W (oil in water) \\
F 2 & O/W (oil in water) \\
F 3 & O/W (oil in water) \\
\hline
\end{tabular}

Keterangan : (F1) Konsentrasi ekstra rambut jagung 1\%; (F2) Konsentrasi ekstra rambut jagung 5\%; (F3) Konsentrasi ekstra rambut jagung $10 \%$.

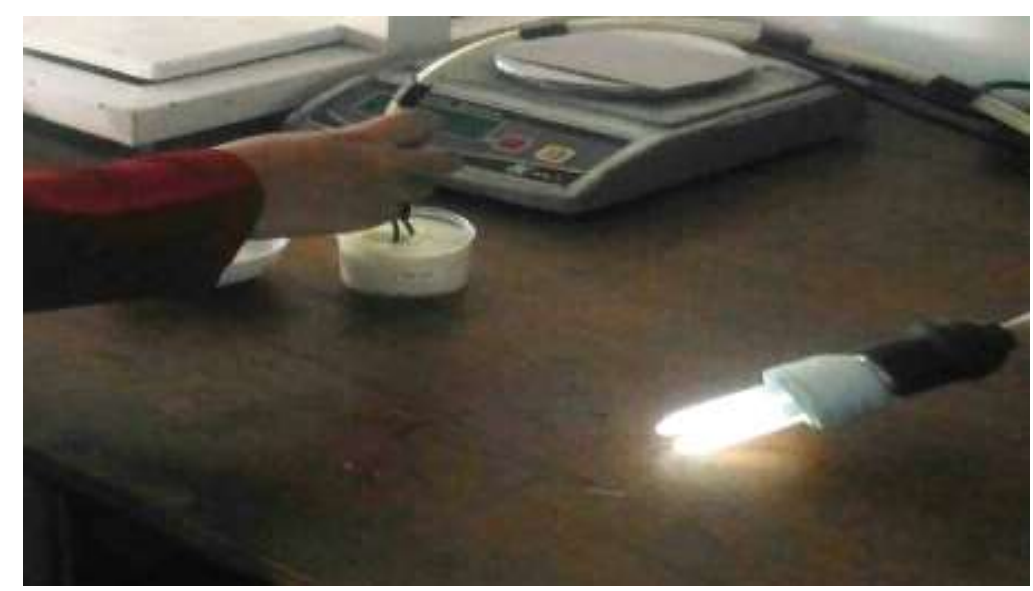

Gambar 2. Hasil uji tipe krim 


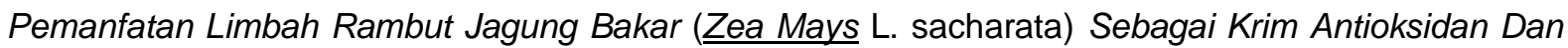
Tabir Surya

Evaluasi berikutnya adalah uji tipe krim menggunakan metode penghantaran listrik. Hasil uji tipe krim menunjukkan bahwa krim yang dihasilkan adalah tipe O/W (oil in water) akan tampak lampu akan menyala ketika kabel dicelupkan ke dalam krim. Hasil uji dapat dilihat pada gambar 2.

Tabel 5. Hasil Pengujian pH Krim Ekstrak Rambut Jagung (Zea Mays L. Sacharata)

\begin{tabular}{cc}
\hline Formula & pH \\
\hline F 1 & $5,87 \pm 0,15$ \\
F 2 & $6,23 \pm 0,31$ \\
F 3 & $6,23 \pm 0,25$
\end{tabular}

Keterangan : (F1) Konsentrasi ekstra rambut jagung 1\%; (F2) Konsentrasi ekstra rambut jagung 5\%; (F3) Konsentrasi ekstra rambut jagung $10 \%$.

Uji $\mathrm{pH}$ bertujuan untuk mengetahui nilai $\mathrm{pH}$ yang dihasilkan oleh sediaan krim agar sesuai dengan persyaratan $\mathrm{pH}$ yang telah ditetapkan. Hasil dari evaluasi mutu fisik $\mathrm{pH}$ sediaan masuk dalam rentang $\mathrm{pH}$ yang telah ditetapkan untuk
$\mathrm{pH}$ fisiologis kulit yaitu 4,5-6,5 sehingga aman untuk pemakaian, karena apabila semakin asam maka akan menyebabkan iritasi pada kulit dan apabila semakin basa akan menyebabkan kulit menjadi kering. ${ }^{11}$

Tabel 6. Hasil Pengujian Uji Daya Sebar Krim Ekstrak Rambut Jagung (Zea Mays L. Sacharata)

\begin{tabular}{cc}
\hline Formula & Daya Sebar (cm) \\
\hline F 1 & $5,65 \pm 0,23$ \\
F 2 & $5,43 \pm 0,10$ \\
F 3 & $5,38 \pm 0,10$
\end{tabular}

Keterangan : (F1) Konsentrasi ekstra rambut jagung 1\%; (F2) Konsentrasi ekstra rambut jagung 5\%; (F3) Konsentrasi ekstra rambut jagung $10 \%$.

Uji daya sebar dilakukan untuk mengetahui daya sebar krim yang dioleskan pada kulit. Semakin besar nilai diameter daya sebar maka semakin luas permukaan yang bisa dijangkau oleh sediaan. Daya sebar yang baik yaitu berada pada rentang nilai $5-7 \mathrm{~cm} .{ }^{1}$ Hasil uji daya sebar didapatkan bahwa pada formulasi 1 , Formulasi 2 dan Formulasi 3 memenuhi rentang uji daya sebar yaitu $5-7 \mathrm{~cm}$. Hasil uji dapat dilihat pada tabel 6 .

Uji daya lekat dilakukan dengan tujuan untuk mengetahui waktu yang dibutuhkan oleh sediaan untuk melekat pada kulit, semakin lama waktu ang dibutuhkan maa semakin lama daya kerja obat. Syarat waktu daya leat yang baik untuk sediaan topikal adalah tidak kurang dari 4 detik. ${ }^{1}$ Hasil uji daya lekat didapatkan hasil pada formulasi 1, Formulasi 2 dan Formulasi 3 menunjukan hasil daya lekat memenuhi syarat uji daya lekat yaitu kurang dari 4 detik. Hasil uji daya lekat dapat dilihat pada tabel 7 .

Tabel 7. Hasil Pengujian Uji Daya Lekat Krim Ekstrak Rambut Jagung (Zea Mays L. Sacharata)

\begin{tabular}{cc}
\hline Formula & Daya Lekat (detik) \\
\hline F 1 & $1,78 \pm 0,09$ \\
F 2 & $1,65 \pm 0,20$ \\
F 3 & $1,71 \pm 0,14$ \\
\hline
\end{tabular}

Keterangan : (F1) Konsentrasi ekstra rambut jagung 1\%; (F2) Konsentrasi ekstra rambut jagung 5\%; (F3) Konsentrasi ekstra rambut jagung $10 \%$. 


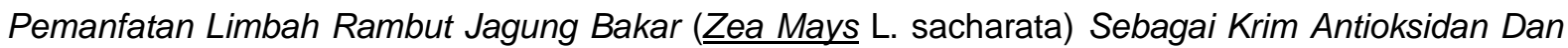
Tabir Surya

Tabel 8. Hasil Pengujian Uji Viskositas Daya Krim Ekstrak Rambut Jagung (Zea Mays L. Sacharata)

\begin{tabular}{cc}
\hline Formula & d.Pa.s \\
\hline F 1 & $421,33 \pm 1,15$ \\
F 2 & $524,67 \pm 0,58$ \\
F 3 & $525,33 \pm 1,53$ \\
\hline
\end{tabular}

Keterangan : (F1) Konsentrasi ekstra rambut jagung 1\%; (F2) Konsentrasi ekstra rambut jagung 5\%; (F3) Konsentrasi ekstra rambut jagung $10 \%$.

Hasil evaluasi viskositas krim

menambah viskositas suatu sediaan krim dan menunjukkan viskositas krim semakin meningkat, dengan meningkatnya konsentrasi ekstrak rambut jagung yang digunakan. Semakin tinggi nilai viskositas maka semain tinggi kekentalannya. Hal tersebut terjadi arena fase lemak zat pengental, surfaktan yang dipilih, proporsi fase terdispersi meningat, konsentrasi emulgator meningkat dan ukuran partikel semakin kecil maka viskositas dari krim akan tinggi. dipengaruhi ekstrak yang kental akan

Tabel 9. Hasil Uji Aktivitas Anti Oksidan Krim Ekstrak Rambut Jagung (Zea Mays L. Sacharata)

\begin{tabular}{cc}
\hline Formula & IC $_{\mathbf{5 0}}$ \\
\hline F 1 & 509,343 \\
F 2 & 462,173 \\
F 3 & 418,194
\end{tabular}

Keterangan : (F1) Konsentrasi ekstra rambut jagung 1\%; (F2) Konsentrasi ekstra rambut jagung 5\%; (F3) Konsentrasi ekstra rambut jagung $10 \%$.

Berdasarkan hasil yang didapat pada

Tabel 9, menunjukkan semakin besar konsentrasi ekstrak rambut mengahsilkan nilan $\mathrm{IC}_{50}$ semakin kecil. Hasil $\mathrm{IC}_{50}$ yang didapat pada krim ekstrak rambut jagung tergolong antioksidan yang sangat lemah tetapi masih berpotensi sebagai anti oksidan. Menurut molyneux (2004) dalam ${ }^{12}$ senyawa anti oksidan dikatakan sangat kuat apabila nilai $\mathrm{IC}_{50}$ 50-100 $\mu \mathrm{g} / \mathrm{mL}$,Sedang apabila nilai $\mathrm{IC}_{50}$ antara $100-150 \mu \mathrm{g} / \mathrm{mL}$, Lemah apabila nilai nilai $\mathrm{IC}_{50}$ $150-200 \mu \mathrm{g} / \mathrm{mL}$, dan sangat lemah bila nilai IC $_{50}$ lebih dari $200 \mu \mathrm{g} / \mathrm{mL}$.

Tabel 10. Perhitungan nilai absorbansi dari krim estrak rambut jagung (Zea Mays L. Sacharata)

\begin{tabular}{cccccccccc}
\hline \multirow{2}{*}{ I } & \multirow{2}{*}{ EE } & \multicolumn{9}{c}{ Basis } & \multicolumn{7}{c}{ Formulasi } \\
\cline { 3 - 10 } & & $\mathbf{I}$ & EE X 1 & I & EE X 1 & I & EE X 1 & I & EE X 1 \\
\hline 290 & 0,015 & 0,407 & 0,006105 & 0,541 & 0,008115 & 0,654 & 0,00981 & 0,949 & 0,014235 \\
295 & 0,0817 & 0,385 & 0,031455 & 0,495 & 0,040442 & 0,614 & 0,050164 & 0,864 & 0,070589 \\
300 & 0,2874 & 0,371 & 0,106625 & 0,476 & 0,136802 & 0,593 & 0,170428 & 0,823 & 0,23653 \\
305 & 0,3278 & 0,367 & 0,120303 & 0,463 & 0,151771 & 0,578 & 0,189468 & 0,801 & 0,262568 \\
310 & 0,1864 & 0,359 & 0,066918 & 0,45 & 0,08388 & 0,568 & 0,105875 & 0,778 & 0,145019 \\
315 & 0,0837 & 0,349 & 0,029211 & 0,444 & 0,037163 & 0,559 & 0,046788 & 0,763 & 0,063863 \\
320 & 0,018 & 0,337 & 0,006066 & 0,433 & 0,007794 & 0,548 & 0,009864 & 0,751 & 0,013518 \\
\hline Jumlah & & & $\mathbf{0 , 3 6 6 6 8 2}$ & & $\mathbf{0 , 4 6 5 9 6 7}$ & & $\mathbf{0 , 5 8 2 3 9 8}$ & & $\mathbf{0 , 8 0 6 3 2 2}$ \\
\hline
\end{tabular}

Keterangan: (EE) Efisiensi Eritema (Ketetapan); (I) Spektrum Simulasi Sinar Surya

Nilai SPF dari beberapa konsentrasi ekstrak didapat dari hasil dari total penjumlahan Efisiensi Eritema dikalikan Spektrum Simulasi Sinar Surya $(E E \times I)$ yang dikalikan Faktor
Korelasi (CF) yaitu 10 yang ditunjukkan pada tabel 10. Hasil nilai SPF masing-masing konsentrasi dapat dilihat pada Tabel 11. 
Pemanfatan Limbah Rambut Jagung Bakar (Zea Mays L. sacharata) Sebagai Krim Antioksidan Dan Tabir Surya

Tabel 11. Nilai SPF Krim Ekstrak Rambut Jagung (Zea Mays L. Sacharata)

\begin{tabular}{cc}
\hline Formula & Nilai SPF \\
\hline Basis Krim & 3,67 \\
F 1 & 4,66 \\
F 2 & 5,82 \\
F 3 & 8,06 \\
\hline
\end{tabular}

Keterangan : (F1) Konsentrasi ekstra rambut jagung 1\%; (F2) Konsentrasi ekstra rambut jagung 5\%; (F3) Konsentrasi ekstra rambut jagung $10 \%$.

Berdasarkan nilai SPF yang

ditampilkan pada Tabel 11. Semakin tinggi konsentrasi ekstrak rambut jagung (Zea Mays

L. Sacharata) pada formulasi krim akan menghasilkan nilai SPF semakin tinggi.

Pembagian tingkat kemampuan tabir surya sebagai berikut: minimal apabila nilai SPF antara 2-4, Sedang apabila nilai SPF antara 46. Ekstrak apabila nilai SPF 6-8, Maksimal apabila nilai SPF antara 8-15 dan Ultra apabila nilai SPF lebih dari 15. Mengacu pada data tersebut nilai SPF yang dihasilkan ekstrak rambut jagung termasuk di sekitaran minimal sampai sedang ${ }^{13}$. Kemampuan menyerap sinar UVB pada sampel krim ekstrak rambut jagung ditunjukkan oleh adanya sistem konjugasi yang terdapat pada senyawa rambut jagung yang mengandung flavonoid, Ikatan rangkap terkonjugasi akan mengalami resonansi selama terkena pancaran sinar UV. ${ }^{3}$

\section{KESIMPULAN}

Berdasarkan penelitian pembuatan krim ekstrak rambut jagung dapat disimpulkan hasil efaluasi mutu fisik memenuhi persyaratan. Hasil uji anti oksidan termasuk kategori sangat lemah dan nilai SPF semakin tinggi konsentrasi ekstrak menghasilkan nilai SPF yang tinggi dan termasuk kategori perlindungan yang maksimal pada Formulasi 3.

\section{UCAPAN TERIMAKASIH}

Terimakasih penelitian ini dibiayai oleh hibah penelitian dosen pemula oleh DP2M
DIKTI dengan nomor kontrak Nomor 084/SP2H/LT/MONO/L7/2019. DAFTAR PUSTAKA

1. Azkiya Z, Ariyani H, Nugraha TS. Evaluasi Sifat Fisik Krim Ekstrak Jahe Merah (Zingiber officinale Rosc. var. rubrum) Sebagai Anti Nyeri. Journal of Current Pharmaceutical Sciences. 2017; 1(1): 1218.

2. Rabima. Uji Stabilitas Formulasi Sediaan Krim Antioksidan Ekstrak Etanol 70\% Dari Biji Melinjo (Gnetum gnemon L.). Indonesia Natural Research Pharmaceutical Journal. 2017; 2(1): 107-121.

3. Laeliocattleya RA, Prasiddha IJ, Estiasih T, Maligan JM, Muchlisyiyah J. Potensi Senyawa Bioaktif Rambut Jagung (Zea Mays L.) Hasil Fraksinasi Bertingkat Menggunakan Pelarut Organik Untuk Tabir Surya Alami. Jurnal Teknologi Pertanian. 2014;15(3):175-184.

4. Svobodová A, Psotová J, Walterová D. Natural phenolics in the prevention of UVinduced skin damage. A review. Biomed Pap Med Fac Univ Palacky Olomouc Czech Repub. 2003;147(2):137-45.

5. Abdiana R, Anggraini DI. Rambut Jagung (Zea mays L.) Sebagai Alternatif Tabir Surya. Majority.2017;7(1):31-35.

6. Nurhanan AR and Wan RWI. Evaluation of Polyphenol Content and Antioxidant Activities of Some Selected Organic and Aqueous Extracts of Cornsilk (Zea mays Hairs). Journal of Medical and Bioengineering (JOMB). 2012:1(1): 48-51.

7. Koloay K, Citraningtyas G, Lolo WA. Uji Efektivitas Ekstrak Etanol Rambut Jagung (Zea mays L.) Terhadap Penurunan Kadar Gula Darah Tikus Putih Jantan Galur Wistar (Rattus norvegicus L.) Yang Diinduksi Aloksan. PHARMACON. 2015;4(3):34-40. 
Pemanfatan Limbah Rambut Jagung Bakar (Zea Mays L. sacharata) Sebagai Krim Antioksidan Dan Tabir Surya

8. Ekowati D, Ningsih D. Formulasi Krim Ekstrak Buah Mengkudu (Morinda citrifolia L.) sebagai Antioksidan. Jurnal Farmasi Indonesia. 2014;11(1):46-53.

9. Handayani V, Ahmad AR, Sudir M. Uji Aktivitas Antioksidan Ekstrak Metanol Bunga dan Daun Patikala (Etlingera elatior (Jack) R.M.Sm) Menggunakan Metode DPPH. Pharm Sci Res. 2014;1(2):86-93.

10. Dirjen POM. Formularium Kosmetika Indonesia. Jakarta, 1985.

11. Rahmawanty D, Yulianti N, Fitriana M. Formulasi dan Evaluasi Masker Wajah
Peel-Off Mengandung Kuersetin dengan Variasi Konsentrasi Gelatin dan Gliserin. Media Farmasi. 2015;12(1): 17-32.

12. Jami'ah SR, Ifaya $M$, Pusmarani J, Nurhikma E. Uji Aktivitas Antioksidan Ekstrak Metanol Kulit Pisang Raja (Musa paradisiaca sapientum) Dengan Metode DPPH (2,2-Difenil-1-Pikrilhidrazil). Jurnal Mandala Pharmacon Indonesia. 2018;4(1):33-38.

13. Damogalad V, Edy HJ, Supriati HS. Formulasi Krim Tabir Surya Ekstrak Kulit Nanas (Ananas comosus L MERR) Dan Uji In Vitro Nilai Sun Protecting Factor (SPF). PHARMACON. 2013;2(2):39-43. 